Article

\title{
Finite Element Modelling of Bandgap Engineered Graphene FET with the Application in Sensing Methanethiol Biomarker
}

\author{
Paramjot Singh (D), Parsoua Abedini Sohi (D) and Mojtaba Kahrizi * \\ Department of Electrical and Computer Engineering, Concordia University, Montreal, QC H3G1M8, Canada; \\ paramjot.singh@concordia.ca (P.S.); parsoua.sohi@concordia.ca (P.A.S.) \\ * Correspondence: mojtaba.kahrizi@concordia.ca; Tel.: +1-51-48-482-424 (ext. 3089)
}

Citation: Singh, P.; Abedini Sohi, P.; Kahrizi, M. Finite Element Modelling of Bandgap Engineered Graphene FET with the Application in Sensing Methanethiol Biomarker. Sensors 2021, 21, 580. https://doi.org/10.3390/ s21020580

Received: 19 December 2020 Accepted: 12 January 2021 Published: 15 January 2021

Publisher's Note: MDPI stays neutral with regard to jurisdictional clai$\mathrm{ms}$ in published maps and institutional affiliations.

Copyright: (C) 2021 by the authors. Licensee MDPI, Basel, Switzerland. This article is an open access article distributed under the terms and conditions of the Creative Commons Attribution (CC BY) license (https:// creativecommons.org/licenses/by/ $4.0 /)$.

\begin{abstract}
In this work, we have designed and simulated a graphene field effect transistor (GFET) with the purpose of developing a sensitive biosensor for methanethiol, a biomarker for bacterial infections. The surface of a graphene layer is functionalized by manipulation of its surface structure and is used as the channel of the GFET. Two methods, doping the crystal structure of graphene and decorating the surface by transition metals (TMs), are utilized to change the electrical properties of the graphene layers to make them suitable as a channel of the GFET. The techniques also change the surface chemistry of the graphene, enhancing its adsorption characteristics and making binding between graphene and biomarker possible. All the physical parameters are calculated for various variants of graphene in the absence and presence of the biomarker using counterpoise energy-corrected density functional theory (DFT). The device was modelled using COMSOL Multiphysics. Our studies show that the sensitivity of the device is affected by structural parameters of the device, the electrical properties of the graphene, and with adsorption of the biomarker. It was found that the devices made of graphene layers decorated with TM show higher sensitivities toward detecting the biomarker compared with those made by doped graphene layers.
\end{abstract}

Keywords: GFET; methanethiol biosensor; COMSOL modelling; bandgap engineering; DFT; functionalized graphene

\section{Introduction}

Yielding monolayer of honeycomb networked carbon $(\mathrm{C})$ atoms from the graphite leads to one of the most promising materials for photonics and electronics research and industry $[1,2]$. $\mathrm{sp}^{2}$ hybridised carbon in this 2D material, called graphene, reveals remarkable electronic and mechanical properties such as very large mobility of charge carriers and high electric and thermal conductivities [1,2]. Graphene is a zero-bandgap material considered to be a semimetal [3] a the property that conceals its functionalities and limits its applications especially for semiconductor technology [4-6]. To overcome this limitation, this hexagonally structured material is transformed into a semiconductor through various band gap engineering methods including creating edge and quantum confinement effects by fabrication of one-dimensional graphene nanoribbons [7-11], passivation with foreign molecules [12,13], as an outcome of straintronics [14,15], and doping with impurities [16,17] and by applying electric field perpendicular to the graphene surface $[18,19]$. Using the above techniques, not only do we induce a gap in the band structure of the graphene, but we are able to tune the gap. Graphene has potential for many applications, such as graphene field effect transistor (GFET) [20-24], photonic devices such as photodetectors [25-30], phototransistors [31-33], and mode-locked lasers [34].

Moreover, due to the high surface-to-volume ratio and the possibility of generating high adsorption site density [35], graphene is extensively used in sensor technology. Schedin et. al. [36] developed the first graphene-based gas sensor. The sensor works based on the change in the hall resistance of the graphene layer as the local carrier concentration 
varies due to the adsorption of $\mathrm{NO}_{2}$ molecules on the surface. Thereafter, researchers work extensively on graphene and its derivatives for sensory activities based on piezoelectric effects [37-40], optical effects [41-43], surface phenomenon [44-46], and others. The contemporary graphene sensor technology is mostly based on a GFET $[20,23,47]$. GFETs are reported for sensing several chemical/biomolecules such as $\mathrm{OH}$ ions [48], monosodium L-glutamate [49], Escherichia coli (E. coli) [50], ethanol [51], glucose [52], hydrogen gas [53], exosomes [54], and nitrogen-based gases [55].

In this report, we model, design, and analyse GFET biosensors. For this, graphene is transmuted into semiconducting material using two methods. The first approach is doping graphene with impurities such as boron (B), aluminium (Al), and gallium $(\mathrm{Ga})$ as n-type and nitrogen $(\mathrm{N})$ phosphorous $(\mathrm{P})$ and arsenic $(\mathrm{As})$ as p-type dopants. Decorating the graphene surface with a transition metal (TM) such as palladium $(\mathrm{Pd})$ is the second technique that we use to manipulate the band gap structure of the graphene. Using these techniques not only allows for transferring of the semimetal graphene to a semiconducting material but also gives the capability to generate and control the concentration of adsorption sites on the surface of graphene layers to attach the biomolecules under investigation. The prepared graphene layers are then used to design GFET-based biosensors to detect biomarkers such as methanethiol.

Methanethiol is volatile organo-sulphur material that is considered as a biomarker for the diseases caused by microorganisms like Helicobacter pylori bacteria (H. pylori) [56], Porphyromonas gingivalis (P. Gingivalis) phylum Bacteroidetes [57,58]. To the best of our knowledge, this is the first time that a graphene-based electronic device is used to detect methanethiol.

Density functional theory (DFT) accompanied by drift-diffusion formalism is used to calculate the physical properties of the semiconducting graphene such as band structure, mobility, and effective density of states. Adsorption energy is also calculated to analyse the surface phenomena on all variants of graphene with or without adsorption of methanethiol. The calculated parameters are used to design and simulate the GFET devices using COMSOL Multiphysics. The dependencies of I-V curves on the electronic properties of the graphene layer as well as the geometrical parameters of the device are considered to evaluate the device's sensing performance.

\section{Device Structure}

The semiconductor module of COMSOL Multiphysics was used to design and simulate a GFET biosensor. The geometrical configuration of the proposed device is illustrated in Figure 1. The device comprises a one-atom-thick graphene monolayer laying on a siliconoxide/silicon $\left(\mathrm{SiO}_{2} / \mathrm{Si}\right)$ substrate. The $\mathrm{SiO}_{2}$ is an insulating layer, serving as a dielectric with a dielectric constant $(\varepsilon r)$ of 3.99. For the sake of calculations, the boundary conditions at all terminals are considered ohmic. I-V measurements were used to determine the performance and characteristics of the device. These measurements were subjected to varying the dimensions of the graphene channel and its surface chemistry (functionalization), the thickness of the dielectric layer, and the doping concentration of the Si substrate.

The graphene layer serves as a channel in the above structure and must be in the semiconducting state. As it was a semimetal material in nature, we needed to manipulate its band structure to transfer it to a semiconductor. Among several methods to induce bandgap in the graphene band structure, we used the following two methods.

In the first method, the graphene was doped with both donors and acceptors, making it compensated. Here, although graphene is doped with impurities, the material remains intrinsic since the concentration of the introduced n-type and p-type dopants will be the same. 


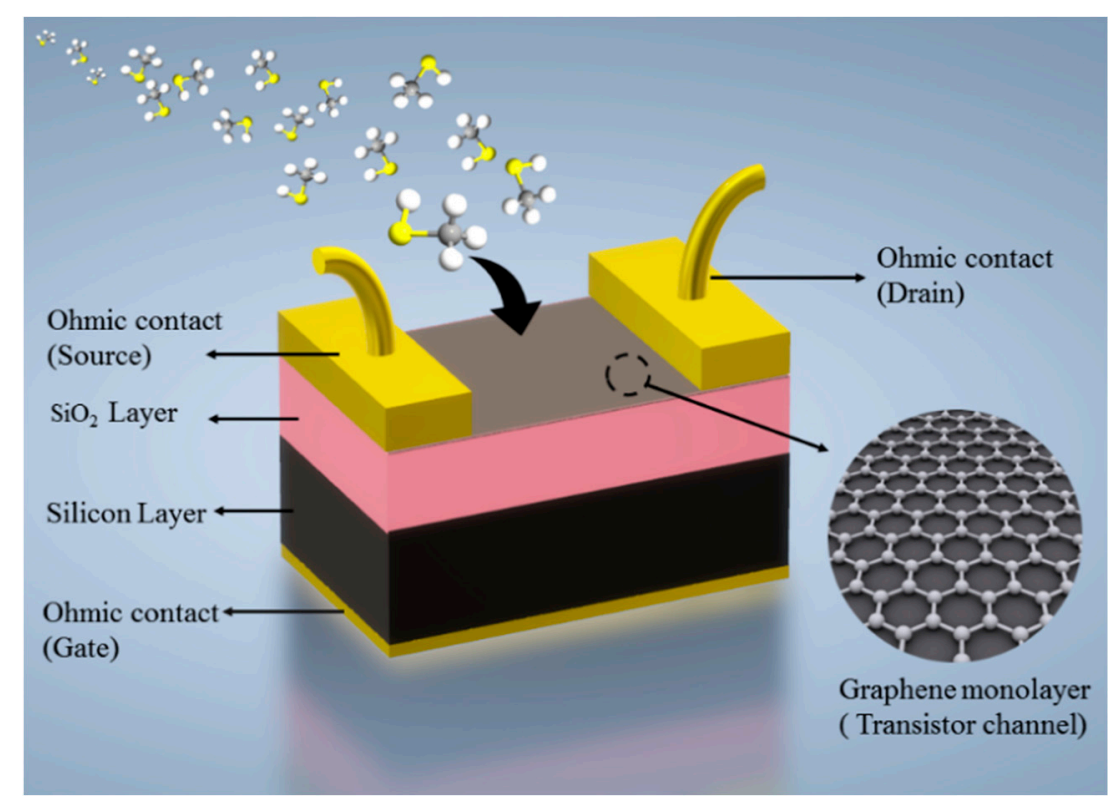

Figure 1. The proposed graphene field effect transistor (GFET) model. The back-gate structure enables binding of the biomarker to the channel surface.

Most common dopants used in graphene are elements from group III for acceptors and from group $\mathrm{V}$ for donors (as carbon is in group IV). In this work, the semiconducting properties of graphene are studied for B-N, Al-P, and Ga-As doping.

In the second method, the bandgap opening for graphene arises by adsorption of TMs to the graphene surface. The adsorption happens without introducing crystal defects in graphene lattice. Among TMs, we used Pd due to its high stability and catalytic activities [59-64]. The electrical properties of the functionalized graphene layer in the absence and presence of the biomarker are crucial parameters to determine the overall sensing performance of the device. These parameters are evaluated precisely by atomistic analytical studies through DFT implemented in Quantum ATK (QATK) software.

\section{Results and Discussion}

3.1. Atomistic Modelling via Quantum ATK

3.1.1. Band Gap Engineering of Graphene

Compensated Doping Method

Figure 2a illustrates the atomic structure of Al-P doped graphene lattice. Optimization is performed to achieve the lowest energy structure and therefore the most stable atomic conformation. The zoomed-in areas in the figure present the calculated $\mathrm{Al}-\mathrm{C}, \mathrm{P}-\mathrm{C}$ and $\mathrm{C}-\mathrm{C}$ bond lengths of a ground-state optimal structure.

In the proposed structure, the $\mathrm{P}$ atom with one extra electron than $\mathrm{C}$ atom acts as an n-type impurity by incorporating one electron per $\mathrm{nm}^{2}$ into the graphene lattice, whereas the $\mathrm{Al}$ atom is one electron deficient and acts as a p-type impurity by incorporating one hole per $\mathrm{nm}^{2}$ to the lattice structure.

After geometry optimization, it was found that co-doping of graphene with Al-P atoms did not destroy the Clar's structure but slightly deformed it, as shown in Figure 2a. Figure $2 b$ illustrates the doped graphene structure with semi-infinite extension in [100] and [010] directions considered for energy-band structure calculations. 

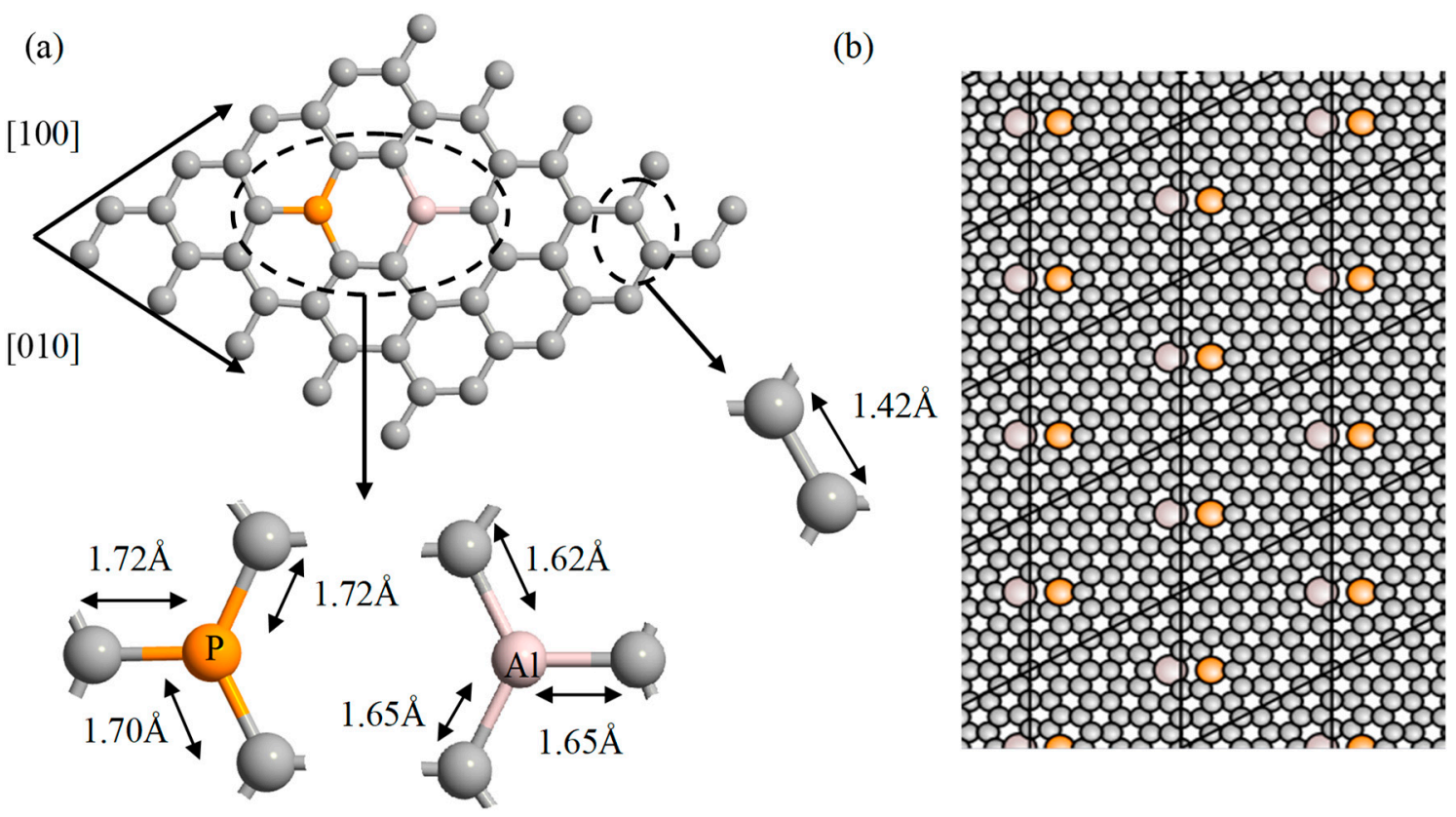

Figure 2. Ground-state optimal structure of Al-P doped graphene; (a) optimized bond lengths of $\mathrm{Al}-\mathrm{C}, \mathrm{P}-\mathrm{C}$, and $\mathrm{C}-\mathrm{C}$; (b) extended structure of co-doped graphene considered for the energy band structure calculations.

The same analyses were also performed for B-N and Ga-As dopants. Each dopant atom was linked with three $\mathrm{C}$ atoms and forms different bond lengths. The bond lengths along with the induced bandgap are summarized in Table 1. All the DFT calculations were performed on the same concentration of dopants of one donor-acceptor pair per $\mathrm{nm}^{2}$. It was found that the Ga-As pair has induced maximum bandgap as compared to other dopants.

Table 1. Induced bandgap and C—dopant bond length in different doped graphene.

\begin{tabular}{ccccc}
\hline Material & B-N Doped & $\begin{array}{c}\text { Al-P Doped } \\
\text { Graphene }\end{array}$ & $\begin{array}{c}\text { Ga-As Doped } \\
\text { Graphene }\end{array}$ \\
\hline Bandgap $(\mathrm{eV})$ & & 0.24 & 0.24 & 0.55 \\
Bond length 1 $(\AA)$ & Acceptor & 1.47 & 1.62 & 1.71 \\
& Donor & 1.4 & 1.7 & 1.7 \\
Bond length 2 $(\AA)$ & Acceptor & 1.47 & 1.65 & 1.72 \\
& Donor & 1.41 & 1.72 & 1.72 \\
Bond length 3 $(\AA)$ & Acceptor & 1.48 & 1.65 & 1.72 \\
& Donor & 1.41 & 1.72 & 1.72 \\
\hline
\end{tabular}

Transition Metal Decoration

TMs have high adsorption capabilities compared to other elements [65]. In this method, a Pd hetero atom was used to functionalize graphene surface [66-72]. The most stable position of a $\mathrm{Pd}$ atom on graphene is a bridge position (the position between two consecutive atoms attached through a bond), as shown in Figure 3a [73]. Mulliken population analysis shows that bond formation between $\mathrm{C}$ and $\mathrm{Pd}$ atom occurs due to interaction between $\mathrm{p}_{\mathrm{z}}$ orbital of $\mathrm{C}$ atom (which is perpendicular to the plane of $\mathrm{C}$ atoms) and $\mathrm{d}$ orbital of Pd valence band. After optimization, bond length between the $\mathrm{Pd}$ and C is $5.44 \AA$, as depicted in Figure 3a. The extended surface of Pd decorated graphene is shown in Figure $3 \mathrm{~b}$ with one Pd atom per $\mathrm{nm}^{2}$. In semiconductor industries, an appropriate concentration of the dopant is usually considered to eliminate the effects of dopant-dopant interaction. In this work, we considered the $1 \mathrm{Pd}$ atom per $1 \mathrm{~nm}^{2}$, by which there will be the least interaction between Pd atoms. 
(a)

(b)

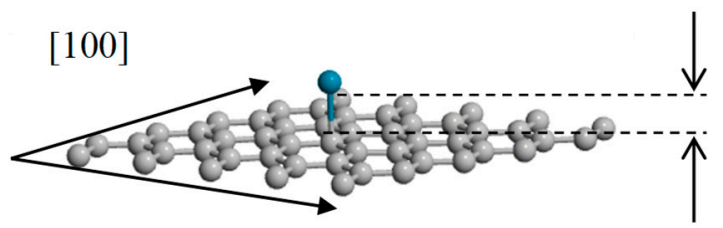

$5.44 \AA$

[010]

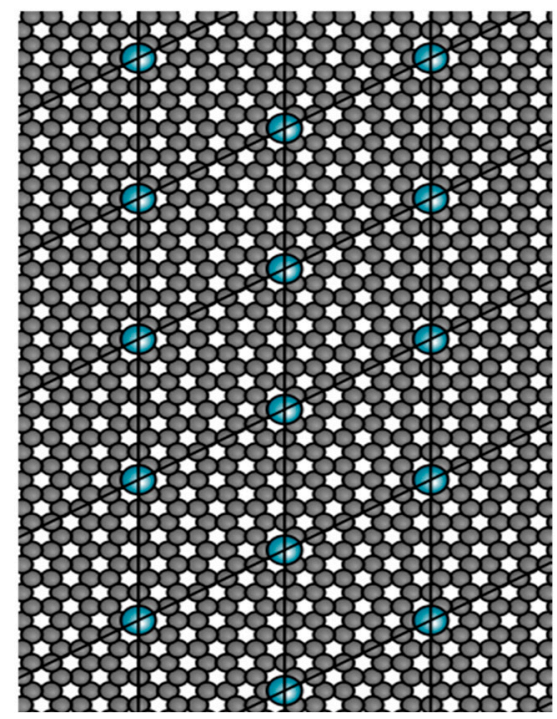

Figure 3. (a) The Pd-decorated graphene structure with C-Pd bond length; (b) extended surface of Pd decorated graphene considered for the energy band structure calculations.

\subsubsection{Interaction with Methanethiol Biomarker}

Characteristics of the interactions between the methanethiol, $\left(\mathrm{CH}_{3} \mathrm{SH}\right)$, and graphene is determined by their binding energy $\left(\mathrm{E}_{\mathrm{AD}}\right)$ [74]. Figure $4 \mathrm{a}, \mathrm{b}$ present the most stable position of methanethiol on the surface of Al-P co-doped and Pd-decorated graphene, respectively, in terms of high adsorption energy.

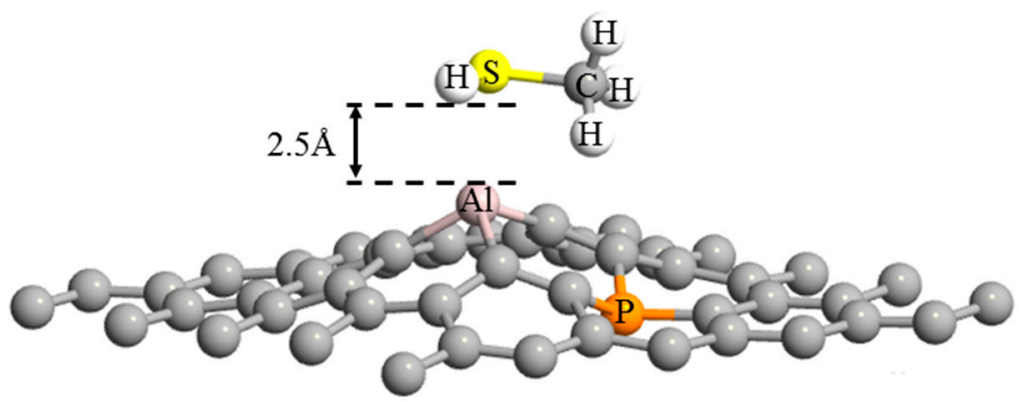

(a)

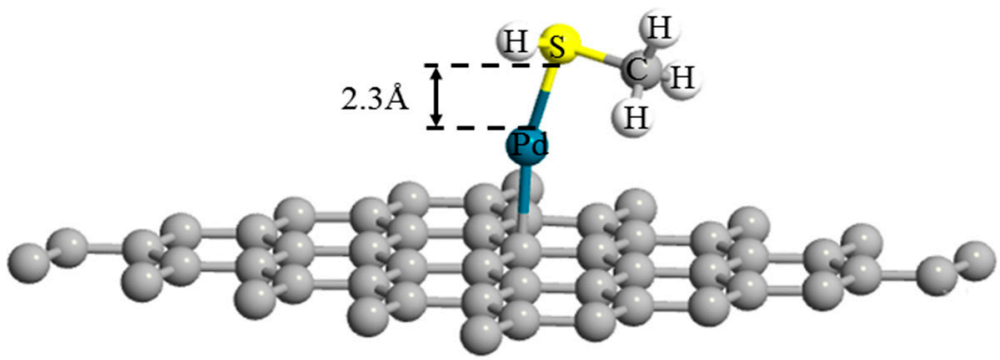

(b)

Figure 4. Optimized structures of graphene-biomolecule complex show (a) physiosorbed methanethiol biomolecule on Al-P-doped graphene lattice and (b) chemisorbed methanethiol biomolecule on Pddecorated graphene lattice.

Compensated doped graphene shows a powerful association with the methanethiol through interaction between sulphur (S) and $\mathrm{Al}$ atoms. As illustrated in the Figure 4a, the 
$\mathrm{Al}$ atom relocates itself by rising towards the methanethiol molecule, causing curvature in the structure. However, there is no chemical bond formed between the biomarker and Al-P co-doped graphene, and adsorption of biomarker by the graphene is due to physisorption phenomena. Even though $\mathrm{P}$ atoms do not show strong enticement towards the biomarker, it plays a crucial role in opening the bandgap of the graphene. A single impurity atom, like $\mathrm{Al}$ or $\mathrm{P}$, opens the Dirac point, but the material remains metallic in nature as some valence bands overlap with Fermi level.

Contrary to what was observed for the case of compensated graphene, Figure $4 \mathrm{~b}$ illustrates that a bond formation occurs between the methanethiol molecule and Pd-decorated graphene. The involvement of an $\mathrm{S}$ atom in bond formation with Pd confirms the occurrence of chemisorption, representing stronger binding between the guest-host complex. Table 2 summarizes the calculated adsorption energies in proposed complexes. The values are counterpoise-corrected interaction energies $\left(\mathrm{E}_{\mathrm{AD}+\mathrm{CP}}\right)$, which correct the errors arising due to overlapping of basis orbitals of the two interacting atoms [74].

Table 2. The total energies, adsorption energies between biomarker and graphene.

\begin{tabular}{cc}
\hline Material & $\mathbf{E}_{\mathrm{AD}+\mathrm{CP}}(\mathbf{e V})$ \\
\hline Methanethiol adsorbed Pd decorated graphene & -1.22 \\
Methanethiol adsorbed B-N doped graphene & -0.01 \\
Methanethiol adsorbed Al-P doped graphene & -0.90 \\
Methanethiol adsorbed Ga-As doped graphene & -0.02 \\
\hline
\end{tabular}

The negative values of the $\mathrm{E}_{\mathrm{AD}+\mathrm{CP}}$ in Table 2 indicates the favourable host-guest molecules adsorption. Furthermore, larger negative $\mathrm{E}_{\mathrm{AD}+\mathrm{CP}}$ corresponds to more efficient adsorption and consequently higher sensing functionalities toward methanethiol. Therefore, the comparison between the values shows that the graphenes doped with B-N and Ga-As do not have efficient adsorption energy towards the indicated biomarker. As a result, for further analyses, we only considered Al-P-doped graphene and Pd-decorated graphene with adsorption energies of $-0.90 \mathrm{eV}$ and $-1.22 \mathrm{eV}$, respectively.

Electrical Properties of Al-P Doped Graphene before and after Interactions with Methanethiol

Figure 5 illustrates the calculated band structure of Al-P-doped graphene before and after methanethiol adsorption. As is seen, methanethiol adsorption increases the bandgap of the graphene from $0.24 \mathrm{eV}$ to $0.45 \mathrm{eV}$. However, the intrinsic behaviour of material remains the same after adsorption.

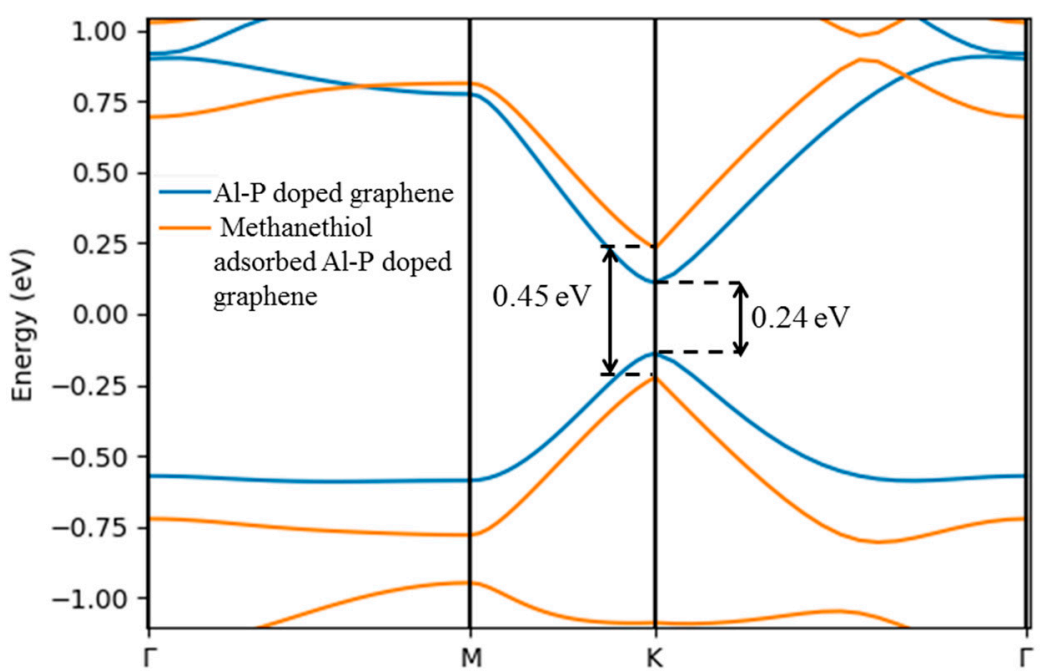

Figure 5. Band structure of Al-P-doped graphene and methanethiol adsorbed Al-P-doped graphene. 
The effective density of states $\left(\mathrm{N}_{\mathrm{c}}\right.$ or $\left.\mathrm{N}_{\mathrm{v}}\right)$ represents the sum of quantum states disseminated on the entire band in the form of two Dirac delta function defined at the edge of the band [75]. $N_{c}\left(N_{v}\right)$ is a function of the carrier mass $\left(m_{e}^{\text {dos }}\right.$ or $\left.m_{h}^{d o s}\right)$ [76]. $m_{e}^{\text {dos }}\left(m_{h}^{d o s}\right)$ is the longitudinal (transverse) effective mass and depends on the valley degeneracy of the energy bands [77]. In all cases, valley degeneracy is constant, which means only the values of longitudinal and transverse effective masses affect the $N_{c}$ and $N_{v}$. The longitudinal and transverse effective mass of electron decrease as conduction band minima (CBM) and valence band maxima (VBM) converge towards the Fermi level, and they become massless at the Dirac point, which is the same as those of intrinsic graphene. After the adsorption of the biomarker, the bandgap increases, and consequently effective masses increase; as a result, $\mathrm{N}_{\mathrm{c}}$ and $\mathrm{N}_{\mathrm{v}}$ increase as tabulated in Table 3. The work function $(\Phi)$ expresses the total amount of energy required to knock out one electron from Fermi level to vacuum level [75] and it is inversely proportional to Fermi energy $\left(\mathrm{E}_{\mathrm{f}}\right)$. Since adsorption of methanethiol decreases $E_{f}$, it leads to increment in the work function of methanethiol adsorbed complexes. As is summarized in Table 3, Al-P-doped graphene has a work function of $4.2 \mathrm{eV}$, which increases to $4.5 \mathrm{eV}$ once the biomarker is adsorbed.

Table 3. Physical parameters of different variants of graphene before and after methanethiol adsorption calculated by DFT analysis.

\begin{tabular}{|c|c|c|c|c|}
\hline & $\begin{array}{l}\text { Al-P Doped } \\
\text { Graphene }\end{array}$ & $\begin{array}{c}\text { Methanethiol } \\
\text { Adsorbed Al-P } \\
\text { Doped } \\
\text { Graphene }\end{array}$ & $\begin{array}{l}\text { Pd Decorated } \\
\text { Graphene }\end{array}$ & $\begin{array}{c}\text { Methanethiol } \\
\text { Adsorbed Pd } \\
\text { Decorated } \\
\text { Graphene }\end{array}$ \\
\hline$E_{g}(e V)$ & 0.24 & 0.45 & 0.018 & 0.026 \\
\hline $\mathrm{E}_{\mathrm{VBM}}-\mathrm{E}_{\mathrm{F}}(\mathrm{eV})$ & 0.12 & 0.23 & 0.011 & 0.019 \\
\hline $\mathrm{E}_{\mathrm{CBM}}-\mathrm{E}_{\mathrm{F}}(\mathrm{eV})$ & 0.12 & 0.23 & 0.007 & 0.007 \\
\hline $\mathrm{E}_{\mathrm{F}}(\mathrm{eV})$ & 5.32 & 4.99 & 4.97 & 4.88 \\
\hline Nature & Semiconductor & Semiconductor & Semiconductor & Semiconductor \\
\hline$\frac{m_{1(\mathrm{e})}}{m_{m}}$ & 0.048 & 0.160 & 0.003 & 0.004 \\
\hline $\begin{array}{l}\mathrm{m}_{\mathrm{e}} \\
\frac{\mathrm{m}_{\mathrm{t}(\mathrm{e})}}{\mathrm{m}}\end{array}$ & 0.099 & 1.909 & 0.007 & 0.010 \\
\hline $\begin{array}{l}\mathrm{m}_{\mathrm{e}} \\
\frac{\mathrm{m}_{\mathrm{t} 2(\mathrm{e})}}{\mathrm{m}}\end{array}$ & 0.092 & 0.174 & 0.005 & 0.008 \\
\hline $\begin{array}{l}m_{e} \\
\frac{m_{1}(h)}{m_{0}}\end{array}$ & 0.052 & 0.164 & 0.003 & 0.004 \\
\hline $\begin{array}{l}m_{e} \\
\frac{m_{t 1(h)}}{m_{e}}\end{array}$ & 0.108 & 2.287 & 0.007 & 0.010 \\
\hline $\begin{array}{l}\frac{m_{e}}{m_{1(h)}} \\
m_{e}\end{array}$ & 0.098 & 0.176 & 0.005 & 0.008 \\
\hline$\frac{\mathrm{m}_{\mathrm{e}}^{\text {dos }}}{\mathrm{m}_{\mathrm{e}}}$ & 0.120 & 0.596 & 0.00748 & 0.011 \\
\hline $\begin{array}{l}\mathrm{m}_{\mathrm{e}} \\
\frac{\mathrm{m}_{\mathrm{h}}^{\mathrm{dos}}}{\mathrm{m}}\end{array}$ & 0.130 & 0.641 & 0.00748 & 0.011 \\
\hline $\begin{array}{l}\mathrm{m}_{\mathrm{e}} \\
\mathrm{N}_{\mathrm{c}}\left(\mathrm{cm}^{-3}\right)\end{array}$ & $1.04 \times 10^{18}$ & $1.15 \times 10^{19}$ & $1.61 \times 10^{16}$ & $2.88 \times 10^{16}$ \\
\hline $\mathrm{N}_{\mathrm{v}}\left(\mathrm{cm}^{-3}\right)$ & $1.17 \times 10^{18}$ & $1.28 \times 10^{19}$ & $1.61 \times 10^{16}$ & $2.88 \times 10^{16}$ \\
\hline$\Phi(\mathrm{eV})$ & 4.200 & 4.500 & 4.010 & 4.700 \\
\hline$\chi(\mathrm{eV})$ & 4.080 & 4.270 & 4.003 & 4.693 \\
\hline$\mu_{\mathrm{e}}\left(\mathrm{cm}^{2} / \mathrm{Vs}\right)$ & $1.25 \times 10^{5}$ & $1.79 \times 10^{4}$ & $9.58 \times 10^{4}$ & $1.28 \times 10^{5}$ \\
\hline$\mu_{\mathrm{h}}\left(\mathrm{cm}^{2} / \mathrm{Vs}\right)$ & $2.29 \times 10^{5}$ & $4.00 \times 10^{4}$ & $3.5 \times 10^{4}$ & $1.90 \times 10^{5}$ \\
\hline
\end{tabular}

Boltzmann Transport Equation (BTE) with relaxation time approximation (RTA) is used to calculate mobility $(\mu)$ in graphene structures. $\mu$ is directly proportional to the relaxation time of carrier $(\mathrm{G})$ [78]. Acoustic phonon scatterings have a major contribution to the value of Tat room temperature. In graphene, there are three acoustic phonon modes: longitudinal acoustic (LA), transverse acoustic (TA), and out-of-plane acoustic (ZA) modes [79]. These modes affect the electron-phonon coupling matrix, which is used to calculate T. As is tabulated in Table 3, our calculations show that carriers mobilities are decreased when methanethiol is adsorbed in Al-P-doped graphene, which affirms that the velocity of the electrons and holes are also decreased. The structural distortion in Al-P graphene during the biomarker adsorption is the major cause of reduction of mobility. 
Electrical Properties of Pd-Decorated Graphene before and after Interactions with Methanethiol

The Pd decorated graphene shows n-type behaviour with a bandgap of $0.018 \mathrm{eV}$. As is illustrated in Figure 6, the adsorption of the biomarker increases the bandgap to $0.026 \mathrm{eV}$.

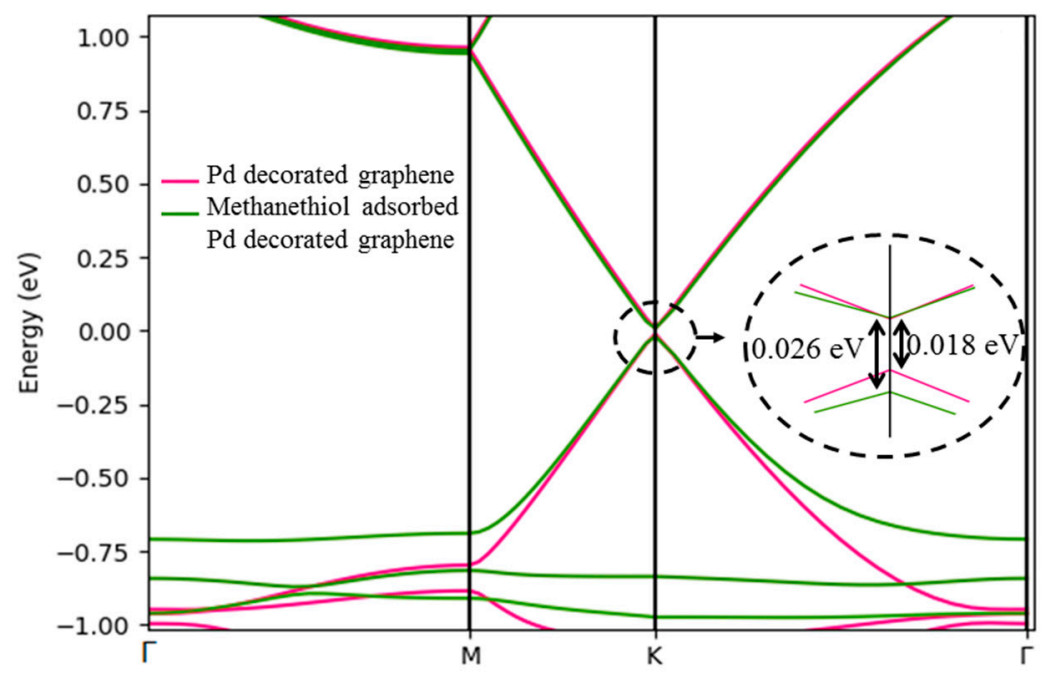

Figure 6. Band structure of Pd-decorated graphene and methanethiol adsorbed Pd-decorated graphene.

Our calculations show that the longitudinal and transverse effective mass of carriers increases as the methanethiol molecule is adsorbed on the graphene. Consequently, $\mathrm{N}_{\mathrm{c}}$ and $\mathrm{N}_{\mathrm{V}}$ also increase with adsorption. Biomarker adsorption also reduces the $\mathrm{E}_{\mathrm{F}}$ of the system as presented in Table 3. Due to the inverse relationship of $E_{F}$ with $\Phi, \Phi$ of Pd-decorated graphene changes from 4.01 to $4.77 \mathrm{eV}$ after adsorption.

Structural distortion increases the phonon scattering in the lattice, which adversely affects the mobility of the material. Decoration of $\mathrm{Pd}$ atom on the graphene decreases the mobility to $10^{5}$ as it creates distortion in lattice. Pd atom acts as a linking agent between graphene and analyte and impedes graphene distortion. Therefore, adsorption of methanethiol increases mobility as summarized in Table 3.

\subsection{Device Characterization via COMSOL}

COMSOL Multiphysics is used to investigate the DC characteristics of the proposed GFET devices. The software efficiently allows assigning physical properties of materials to model the device. The investigated semiconducting properties of the functionalized graphene in the presence and absence of the biomarker (as summarized in Table 3) are applied in the material properties section required by the model.

The Al-P doped GFET (AlP-GFET) and Pd decorated GFET (Pd-GFET) performances are characterized by considering the effect of geometrical and physical parameters of the devices.

The impact of device parameters variation on the sensitivity of the sensor is discussed in the following sections.

\subsubsection{Characteristics of Device}

A GFET is a three-electrode device, composed of a graphene channel between two electrodes and a gate contact to modulate the electronic response of the channel. In this section, the electrical characteristics of the AIP-GFET and Pd-GFET devices in the absence of biomarkers are evaluated. For these analyses, the channel length (L, the source-drain spacing) and channel width (W) of the device are considered $2 \mu \mathrm{m}$ and $1 \mu \mathrm{m}$, respectively. A p-type Si with the doping concentration of $10^{18} \mathrm{~cm}^{-3}$ is used as the substrate. While the source is grounded, the drain current $\left(\mathrm{I}_{\mathrm{d}}\right)$ is measured by sweeping the gate voltage $\left(\mathrm{V}_{\mathrm{g}}\right)$ from 0 to $2 \mathrm{~V}$ at a drain voltage $\left(\mathrm{V}_{\mathrm{d}}\right)$ of $10 \mathrm{mV}$. I-V characteristics of the devices are 
shown in Figure 7a (AlP-GFET) and Figure 7b (Pd-GFET). Two distinct regions appear in the graphs: negative differential resistance (NDR) and the positive differential resistance (PDR). A minimum happens as these two regions meet, which is known as the Dirac point at gate voltage, $\mathrm{V}_{\mathrm{n}}$ (neutral voltage). According to the graphs, the $\mathrm{V}_{\mathrm{n}}$ of $0.93 \mathrm{~V}$ and $1.09 \mathrm{~V}$ were observed for AlP-GFET and Pd-GFET, respectively.

(a)

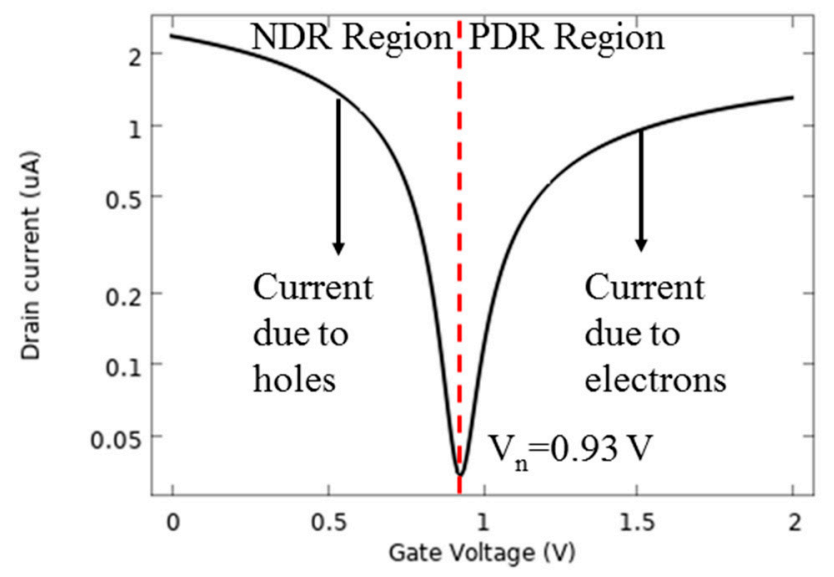

(b)

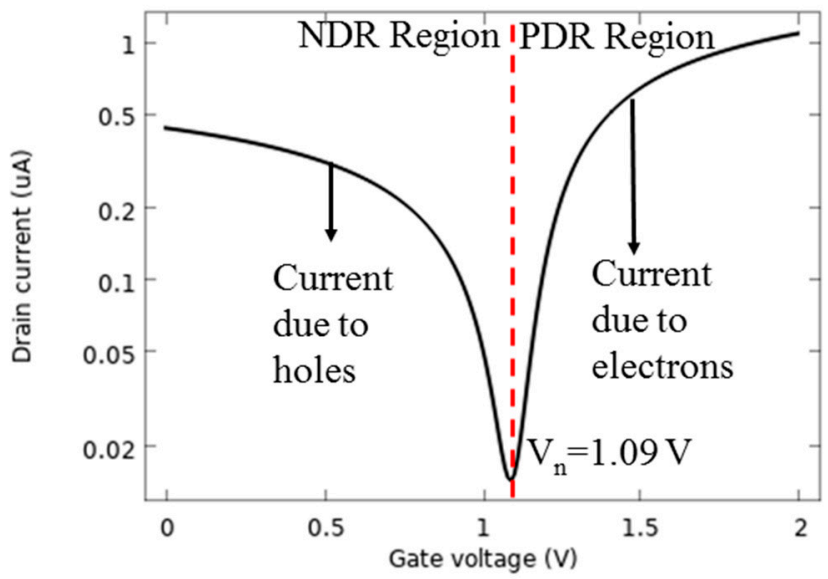

Figure 7. I-V characteristics show two distinct regions and the particular $V_{n}$ for (a) AlP-GFET, (b) Pd-GFET.

This peculiar behaviour of the I-V characteristics of the device is due to the ambipolar transport nature of graphene, which implies the coupled motion of holes and electrons. Therefore, the charge carrier concentration along the graphene channel gives more insight into the $\mathrm{I}_{\mathrm{d}}-\mathrm{V}_{\mathrm{g}}$ curve discussed in Figure 7.

The density of the carriers for AlP-GFET and Pd-GFET devices versus the gate voltage are shown in Figure 8a,b, respectively. The figure shows that the holes are the majority carrier when the value of $V_{g}$ is below the value of $V_{n}$ of the device. At $V_{n}$, the concentration of both carriers is equal, and as $V_{g}$ increases beyond $V_{n}$, a channel inversion is observed and the electrons will dominate the carrier concentrations.

(a)

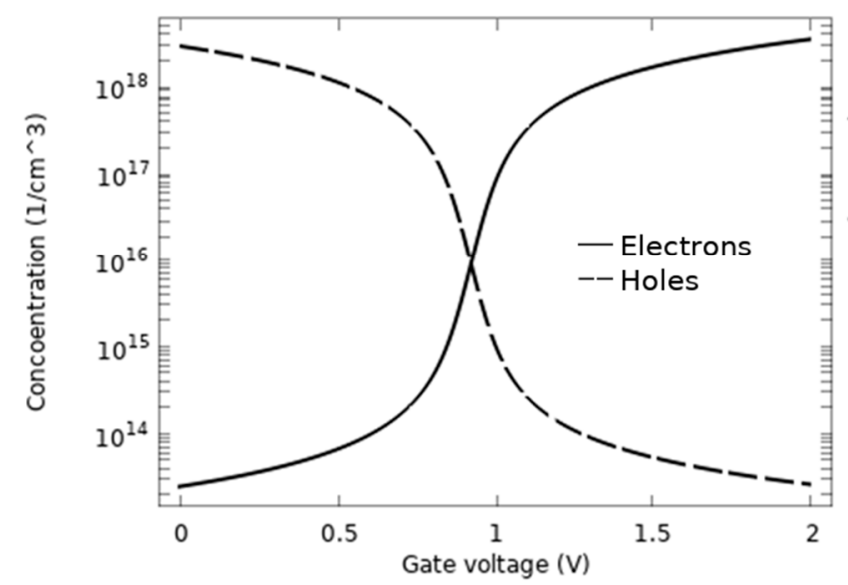

(b)

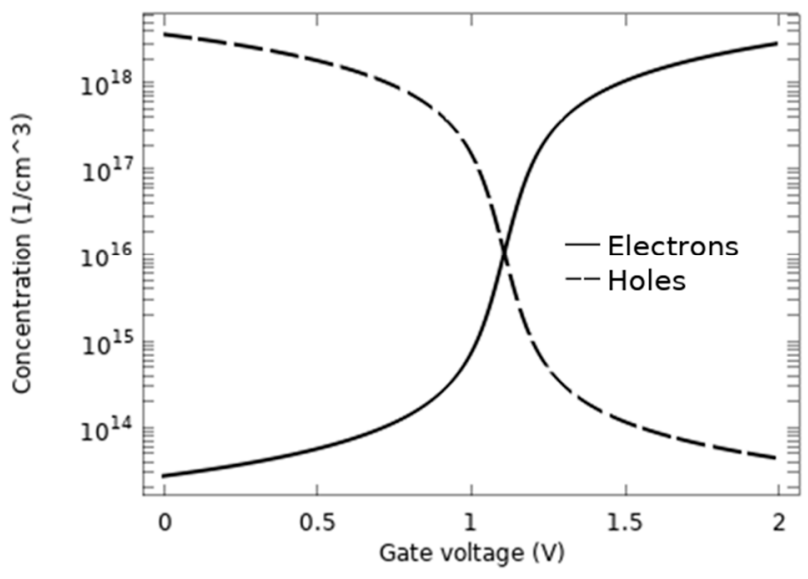

Figure 8. Carrier concentration in the graphene channel versus $V_{g}$ for (a) AlP-GFET, (b) Pd-GFET. This confirms the occurrence of inversion of the device channel at $V_{n}$.

The conductance of the channel is determined by the abundance of charge carriers, which is influenced by the applied gate voltage. The conductance, in return, determines 
the $I_{d}$. Therefore, in Figure 7 , the negative slope of $I_{d}$ in the NDR region corresponds to the decreasing.

The trend of carrier hole concentration and the positive slope of $I_{d}$ in the PDR region correspond to the increasing trend of the carrier electron concentration.

Figure 9a illustrates the $I_{d}-V_{g}$ curve of AlP-GFET at different drain voltages. It is observed that with an increment of the drain voltage, the I-V curve shifts toward the higher current values. The $V_{n}$ of $0.93 \mathrm{~V}$ remains nearly constant for all $\mathrm{V}_{d}$ values. $\mathrm{I}_{d}-\mathrm{V}_{\mathrm{g}}$ characteristics of Pd-GFET shown in Figure 9b follow the same trend as discussed for AlP-GFET. For this device, $\mathrm{V}_{\mathrm{n}}$ is at the voltage of $1.09 \mathrm{~V}$, which is higher than what is observed for AlP-GFET. Moreover, the lower current intensity of Pd-GFET is due to the lower carrier mobilities in this device compared to AlP-GFET, as summarized in Table 3.

(a)

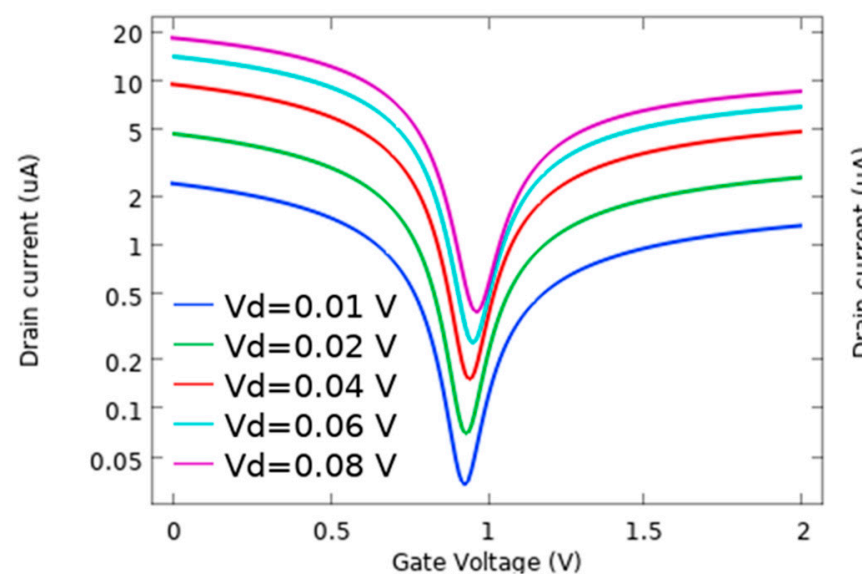

(b)

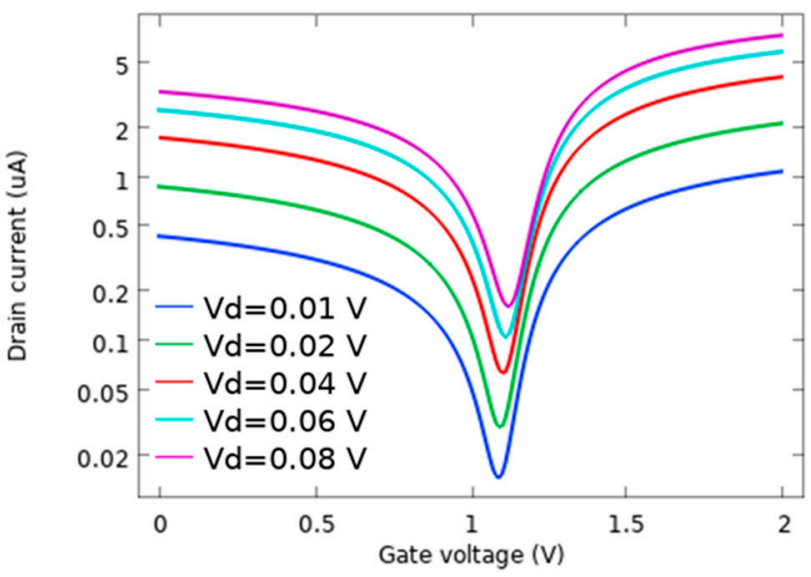

Figure 9. I-V characteristics as a function of applied $V_{d}$ for (a) Al-P doped GFET (b), Pd-decorated GFET. According to the graphs, $\mathrm{V}_{\mathrm{n}}$ of the devices remains constant as $\mathrm{V}_{\mathrm{d}}$ varies.

To give a more authenticated perception to the device study, $I_{d}-V_{g}$ curves were calculated at $\mathrm{V}_{\mathrm{d}}$ of $10 \mathrm{mV}$ for the devices with different channel dimensions $(\mathrm{W} \times \mathrm{L})$. Figure 10a presents the obtained results for the AlP-GFET devices, and Figure 10b presents those for Pd-GFET devices. As the results show, the value of $V_{n}$ for both devices remains constant and is independent of the device geometry. This is one of the positive characteristics of the device that shows the sensing properties of the device will not be affected by the structural device dimensions. However, the device $I_{d}$ is a function of channel length and width, $I_{d} \propto \frac{W}{L}$. The effect of the channel dimension on the device $I_{d}$ follows the following equation [80].

$$
I_{d}=\frac{W}{L} \int_{V_{s}}^{V_{d}}\left(q \mu_{p} p+q \mu_{n} n+q \frac{\mu_{p}+\mu_{n}}{2} n_{p u d}\right)
$$

where the parameters $W$ and $L$ are width and length of the channel, respectively; $\mu_{n}$ and $\mu_{\mathrm{p}}$ are electron and hole mobility, respectively; and $\sigma=q \mu_{\mathrm{n}} \mathrm{n}+\mathrm{q} \mu_{\mathrm{p}} \mathrm{p}$ is the conductivity of the channel. The term, $\mathrm{q} \frac{\mu_{\mathrm{p}}+\mu_{\mathrm{n}}}{2} \mathrm{n}_{\text {pud }}$ denotes that the residual charge occurs due to the spatial homogeneity. 
(a)

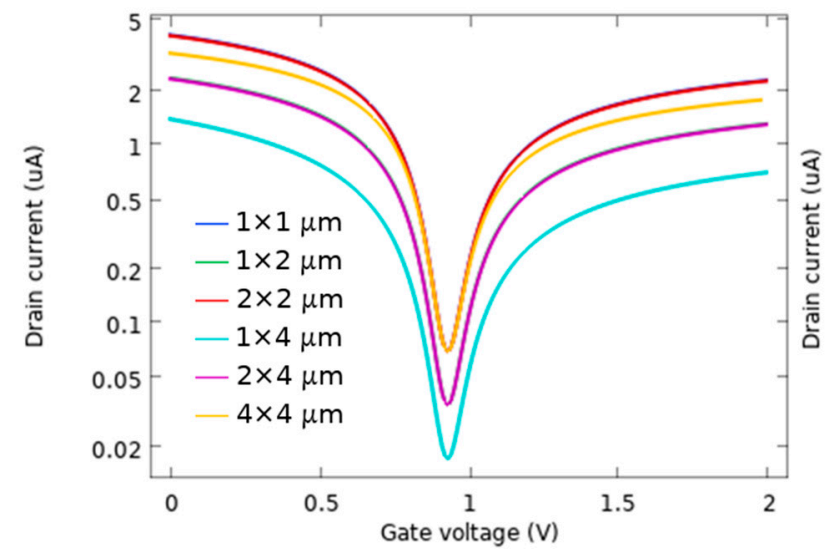

(b)

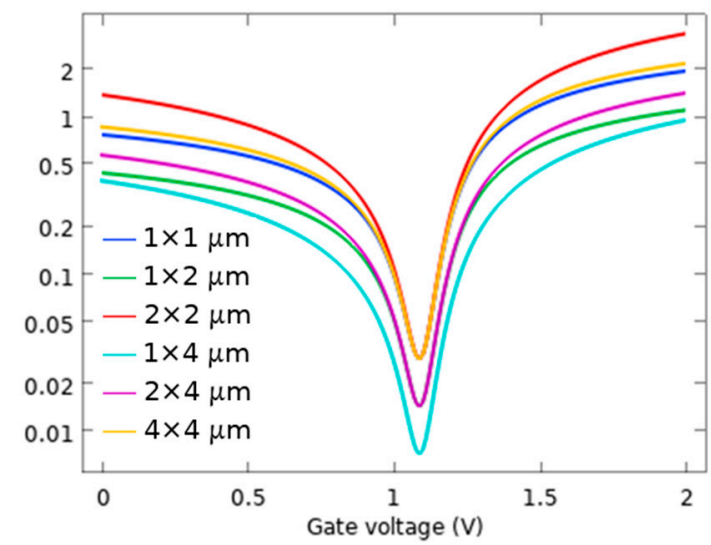

Figure 10. I-V characteristics as a function of channel dimension $(\mathrm{W} \times \mathrm{L})$, for $(\mathbf{a})$ AlP-GFET $(\mathbf{b})$ Pd-GFET. The $\mathrm{I}_{\mathrm{d}}$ of the devices with equal $\frac{\mathrm{W}}{\mathrm{L}}$ ratios are overlapped.

We also investigated the characteristics of the device with respect to electrical properties of the silicon substrate for both variants of the device. The results show that they have a significant effect on the value of $\mathrm{V}_{\mathrm{n}}$ as we change the doping type and its concentration of the substrate. The I-V characteristics in Figure 11a (AlP-GFET) and Figure 11b (Pd-GFET) illustrate that as the concentration of dopants increases, the position of $V_{n}$ moves toward higher voltages for p-type substrates, while it moves toward lower voltages for the n-type substrate case.

(a)

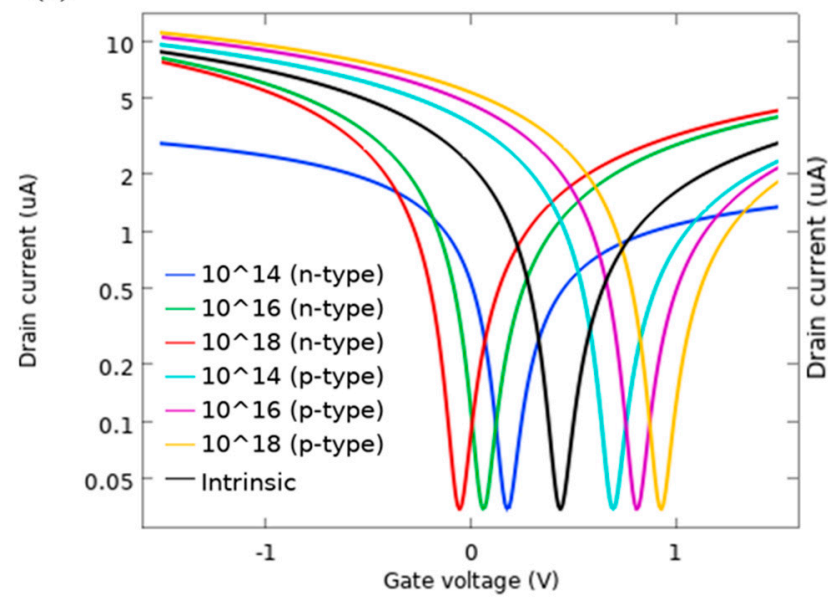

(b)

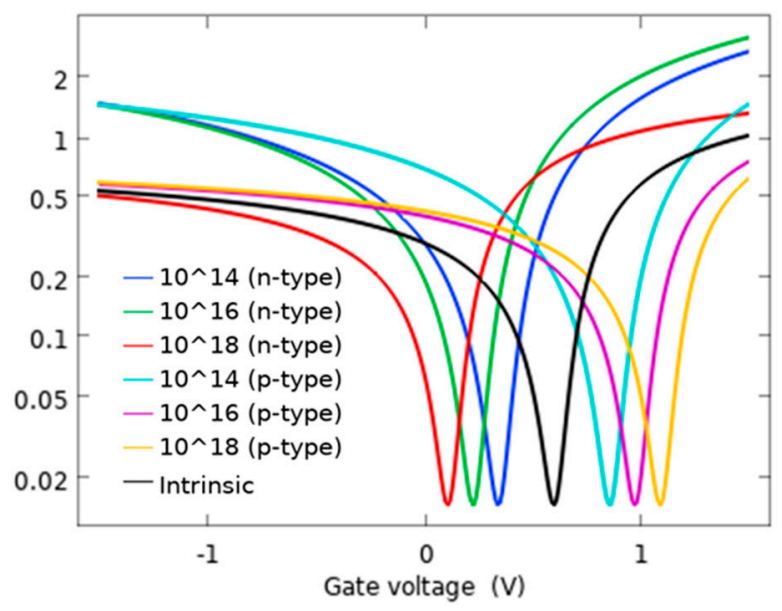

Figure 11. I-V characteristics as a function of doping type and concentration for (a) AlP-GFET, (b) Pd- GFET.

Figure 12a shows the measured $\mathrm{I}_{\mathrm{d}}-\mathrm{V}_{\mathrm{g}}$ for the AlP-GFET device, and Figure $12 \mathrm{~b}$ shows it for the Pd-GFET device for two different oxide thicknesses, $200 \mathrm{~nm}$ and $400 \mathrm{~nm}$. According to the graphs, the variation of the oxide layer thickness does not affect the sensing properties of the devices as the value of $V_{n}$ remains the same for both cases.

\subsubsection{Detection of Methanethiol Biomarker}

To check the sensitivity of the device against biomarkers, the device DC characteristics are typically evaluated in the presence of a biomarker and compared with a reference test in the absence of biomarkers. 
(a)

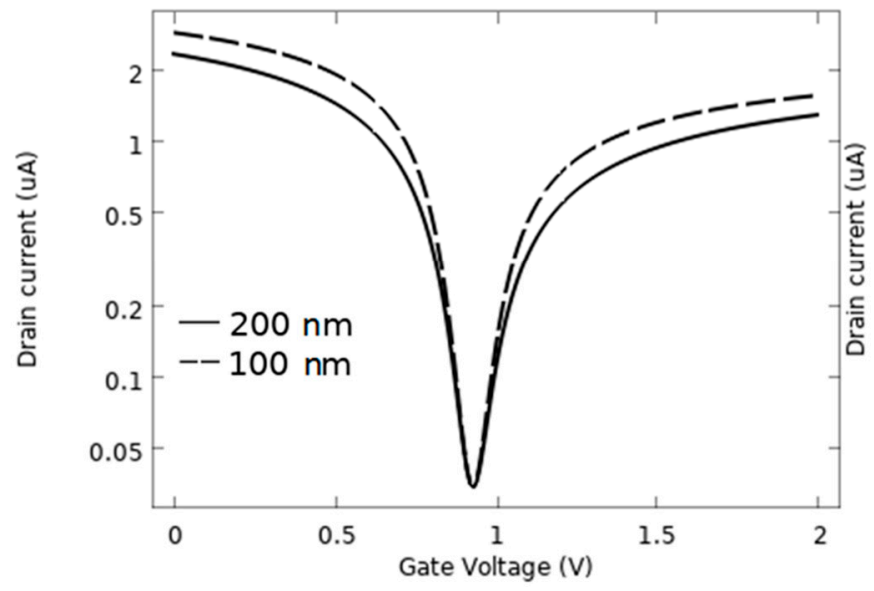

(b)

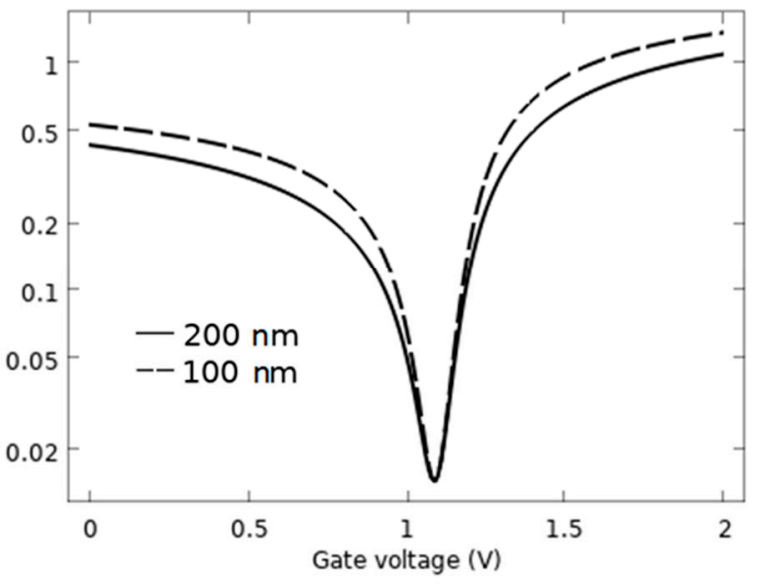

Figure 12. I-V characteristics as a function of dielectric layer thickness (a) AlP-GFET (b) Pd-GFET.

For this study, a device with channel dimensions of $1 \times 2 \mu \mathrm{m}^{2}(\mathrm{~W} \times \mathrm{L})$ and a p-type substrate with doping concentration $10^{18} \mathrm{~cm}^{-3}$ is considered. $V_{\mathrm{g}}$ is swept from 0 to $2 \mathrm{~V}$, while a constant $V_{d}$ of $10 \mathrm{mV}$ is applied on the drain. One biomolecule per $\mathrm{nm}^{2}$ was considered for the adsorption concentration of the biomarker on the graphene layer.

Figure 13a illustrates the $I_{d}-V_{g}$ characteristics of the AlP-GFET device, and Figure 13b illustrates it for the Pd-GFET device, in the presence of the methanethiol as compared to a reference test in absence of the biomarker.

(a)

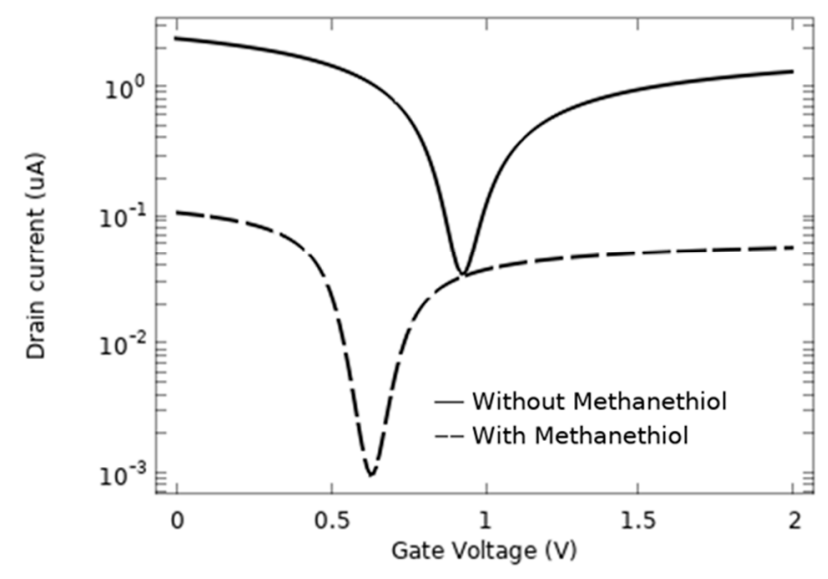

(b)

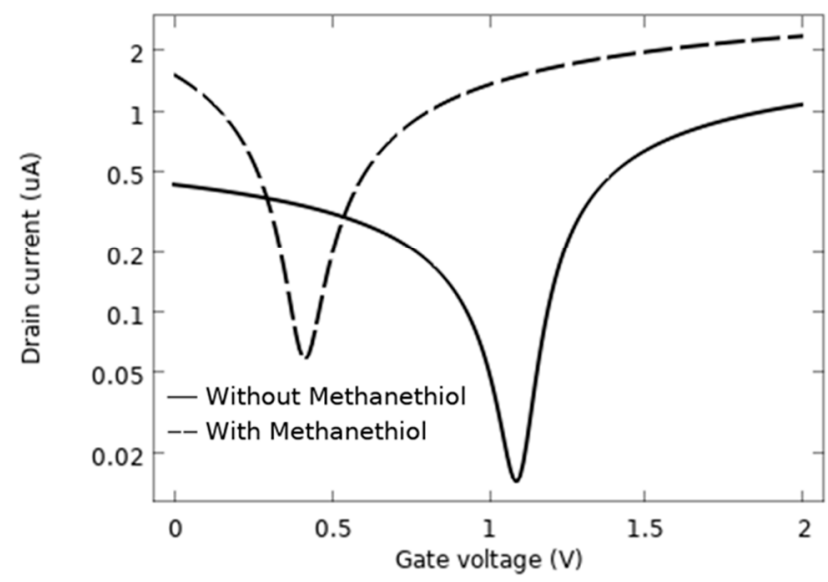

Figure 13. I-V characteristics before and after adsorption of methanethiol for (a) AlP-GFET, (b) Pd-GFET.

$I_{d}-V_{g}$ curves obtained for AlP-GFET show a clear shift in $V_{n}$ from $0.93 \mathrm{~V}$ to $0.63 \mathrm{~V}$ after the adsorption of methanethiol by the channel surface, while for the Pd-GFET, it changed from $1.09 \mathrm{~V}$ to $0.42 \mathrm{~V}$. The shift in $\mathrm{V}_{\mathrm{n}}$ is attributed to the change of $\mu$, bandgap, $\mathrm{N}_{\mathrm{c}}$ or $\mathrm{N}_{\mathrm{v}}$, and $\Phi$ of the functionalized graphene once it is exposed to the methanethiol molecule. As summarized in Table 3, these physical quantities show variation after adsorption of methanethiol, which affects the $V_{n}$ value. The observed shift in $V_{n}$ for the Pd-GFET is larger than that of the AlP-GFET, which affirms the higher sensitivity to the biomarker for this device.

It is observed that the overall current intensity for AlP-GFET decreases after the adsorption of the biomarker. However, for the case of Pd-GFET, the intensity of the current slightly increases after biomarker adsorption. This behaviour of the device corresponds to 
the effect of adsorption on the carrier mobility of the graphene channel (as summarized in Table 3). The increase in mobility of the carriers will be correlated with an increase in $I_{d}$ of the device and vice versa.

Based on the results discussed in Section 3.2.1, the $V_{n}$ of the device is only a function of semiconductive properties of the graphene channel and varies by functionalization of the graphene and its interaction with the molecules. The geometry of the device and the biasing parameters does not alter the $V_{n}$, and therefore the sensitivity of the sensors towards exposure to methanethiol could be simply defined as $S \cong\left|\frac{\Delta \mathrm{Vn}}{\mathrm{Vn}}\right|$. The calculated sensitivity of the AlP-GFET towards methanethiol when the $V_{\mathrm{n}}$ changes from $0.93 \mathrm{~V}$ to $0.63 \mathrm{~V}$ is $32.25 \%$; similarly, $\mathrm{V}_{\mathrm{n}}$ in the Pd-GFET changes from $1.09 \mathrm{~V}$ to $0.42 \mathrm{~V}$, which shows $60.55 \%$ sensitivity towards this biomarker.

There are other reports in the literature regarding applying methanethiol as a biomarker to develop biosensors [81-83]. Compared to those, the present work proposes a design to develop a device with higher sensitivity and simpler structure.

\section{Conclusions}

In this work, we demonstrated the possibility of using a GFET biosensor for the detection of methanethiol biomarker, which is used to identify diseases caused by microorganisms such as Helicobacter pylori bacteria (H. pylori) and Porphyromonas gingivalis (P. Gingivalis) phylum Bacteroidetes. Surface chemistry of the graphene layers is manipulated using two methods: (a) doping the graphene crystals and (b) decorating the surface of the graphene with TMs before using it as the channel of the GFET. The device was designed and characterized using COMSOL Multiphysics. The NDR characteristic of the graphene, which is due to its ambipolar behaviour, was observed using three-terminal measurements. The deep that appeared in the I-V characteristics of the device is used to study the sensitivity of the sensors. The results show that the device characteristic is only sensitive to the doping level of the silicon substrate; otherwise, it is independent of other physical parameters of the device. However, our investigations show that electrical properties of the functionalized graphene layers particularly in the absence and presence of the biomarkers are largely affected the characteristics of the sensor. The device is more sensitive to the adsorbed biomarker in the case of Pd-GFET compared to the devices developed using Al-P doping.

Author Contributions: Conceptualization, P.S., P.A.S. and M.K.; methodology, P.A.S.; software, P.S.; validation, P.S., P.A.S. and M.K.; formal analysis, P.S., P.A.S. and M.K.; investigation, P.S.; resources, M.K.; data curation, P.A.S. and M.K.; writing-original draft preparation, P.S.; writing—review and editing, P.A.S. and M.K.; visualization, P.S.; supervision, M.K.; project administration, P.A.S. and M.K.; funding acquisition, M.K. All authors have read and agreed to the published version of the manuscript.

Funding: This work was partially supported by the Natural Sciences and Engineering Research Council of Canada (NSERC) and by the Gina Cody School of Engineering and Computer Science at Concordia University.

Institutional Review Board Statement: Not applicable.

Informed Consent Statement: Not applicable.

Data Availability Statement: The data that support the findings of this study are available from the corresponding author upon reasonable request.

Conflicts of Interest: The authors declare no conflict of interest.

\section{References}

1. Schwierz, F. Graphene transistors. Nat. Nanotechnol. 2010, 5, 487-496. [CrossRef] [PubMed]

2. Grigorenko, A.N.; Polini, M.; Novoselov, K.S. Graphene plasmonics. Nat. Photonics 2012, 6, 749-758. [CrossRef]

3. Gui, G.; Li, J.; Zhong, J. Band structure engineering of graphene by strain: First-principles calculations. Phys. Rev. B Condens. Matter Mater. Phys. 2008, 78, 1-6. [CrossRef] 
4. Barone, V.; Hod, O.; Scuseria, G.E. Electronic Structure and Stability of Semiconducting Graphene Nanoribbons. Nano Lett. 2006, 6, 2748-2754. [CrossRef] [PubMed]

5. Lu, G.; Yu, K.; Wen, Z.; Chen, J. Semiconducting graphene: Converting graphene from semimetal to semiconductor. Nanoscale 2013, 5, 1353. [CrossRef]

6. Prestigiacomo, J.C.; Nath, A.; Osofsky, M.S.; Hernández, S.C.; Wheeler, V.D.; Walton, S.G.; Gaskill, D.K. Determining the nature of the gap in semiconducting graphene. Sci. Rep. 2017, 7, 1-5. [CrossRef]

7. Fang, T.; Konar, A.; Xing, H.; Jena, D. Mobility in semiconducting graphene nanoribbons: Phonon, impurity, and edge roughness scattering. Phys. Rev. B Condens. Matter Mater. Phys. 2008, 78, 1-8. [CrossRef]

8. Wang, Z.F.; Jin, S.; Liu, F. Spatially separated spin carriers in spin-semiconducting graphene nanoribbons. Phys. Rev. Lett. 2013, 111, 1-5. [CrossRef]

9. Li, X.; Wang, X.; Zhang, L.; Lee, S.; Dai, H. Chemically derived, ultrasmooth graphene nanoribbon semiconductors. Science 2008, 319, 1229-1232. [CrossRef]

10. Jacobberger, R.M.; Arnold, M.S. High-Performance Charge Transport in Semiconducting Armchair Graphene Nanoribbons Grown Directly on Germanium. ACS Nano 2017, 11, 8924-8929. [CrossRef]

11. Cai, J.; Ruffieux, P.; Jaafar, R.; Bieri, M.; Braun, T.; Blankenburg, S.; Muoth, M.; Seitsonen, A.P.; Saleh, M.; Feng, X.; et al. Atomically precise bottom-up fabrication of graphene nanoribbons. Nature 2010, 466, 470-473. [CrossRef] [PubMed]

12. Singh, S.; Kaur, I. Bandgap engineering in armchair graphene nanoribbon of zigzag-armchair-zigzag based Nano-FET: A DFT investigation. Phys. E Low-Dimens. Syst. Nanostruct. 2020, 118, 113960. [CrossRef]

13. AlZahrani, A.Z.; Srivastava, G.P. Structural and electronic properties of H-passivated graphene. Appl. Surf. Sci. 2010, 256, 5783-5788. [CrossRef]

14. Verberck, B.; Partoens, B.; Peeters, F.M.; Trauzettel, B. Strain-induced band gaps in bilayer graphene. Phys. Rev. B Condens. Matter Mater. Phys. 2012, 85, 1-10. [CrossRef]

15. Sahalianov, I.Y.; Radchenko, T.M.; Tatarenko, V.A.; Cuniberti, G.; Prylutskyy, Y.I. Straintronics in graphene: Extra large electronic band gap induced by tensile and shear strains. J. Appl. Phys. 2019, 126. [CrossRef]

16. Huang, B. Electronic properties of boron and nitrogen doped graphene nanoribbons and its application for graphene electronics. Phys. Lett. Sect. A Gen. At. Solid State Phys. 2011, 375, 845-848. [CrossRef]

17. Nath, P.; Sanyal, D.; Jana, D. Semi-metallic to semiconducting transition in graphene nanosheet with site specific co-doping of boron and nitrogen. Phys. E Low-Dimens. Syst. Nanostruct. 2014, 56, 64-68. [CrossRef]

18. Avetisyan, A.A.; Partoens, B.; Peeters, F.M. Electric field tuning of the band gap in graphene multilayers. Phys. Rev. B Condens. Matter Mater. Phys. 2009, 79, 1-7. [CrossRef]

19. Sławińska, J.; Zasada, I.; Klusek, Z. Energy gap tuning in graphene on hexagonal boron nitride bilayer system. Phys. Rev. B Condens. Matter Mater. Phys. 2010, 81, 1-9. [CrossRef]

20. Kanai, Y.; Ohmuro-Matsuyama, Y.; Tanioku, M.; Ushiba, S.; Ono, T.; Inoue, K.; Kitaguchi, T.; Kimura, M.; Ueda, H.; Matsumoto, K. Graphene Field Effect Transistor-Based Immunosensor for Ultrasensitive Noncompetitive Detection of Small Antigens. ACS Sens. 2020, 5, 24-28. [CrossRef]

21. Salehi-Khojin, A.; Estrada, D.; Lin, K.Y.; Bae, M.-H.; Xiong, F.; Pop, E.; Masel, R.I. Graphene Sensors: Polycrystalline Graphene Ribbons as Chemiresistors. Adv. Mater. 2012, 24, 52. [CrossRef]

22. Soltani, A.; Kuschewski, F.; Bonmann, M.; Generalov, A.; Vorobiev, A.; Ludwig, F.; Wiecha, M.M.; Čibiraitè, D.; Walla, F.; Winnerl, S.; et al. Direct nanoscopic observation of plasma waves in the channel of a graphene field-effect transistor. Light Sci. Appl. 2020, 9. [CrossRef] [PubMed]

23. Salehirozveh, M.; Dehghani, P.; Zimmermann, M.; Roy, V.A.L.; Heidari, H. Graphene Field Effect Transistor Biosensors based on Aptamer for Amyloid- $\beta$ Detection. IEEE Sens. J. 2020, 20, 12488-12494. [CrossRef]

24. Fakih, I.; Durnan, O.; Mahvash, F.; Napal, I.; Centeno, A.; Zurutuza, A.; Yargeau, V.; Szkopek, T. Selective ion sensing with high resolution large area graphene field effect transistor arrays. Nat. Commun. 2020, 11, 1-12. [CrossRef]

25. De Nicola, F.; Puthiya Purayil, N.S.; Miŝeikis, V.; Spirito, D.; Tomadin, A.; Coletti, C.; Polini, M.; Krahne, R.; Pellegrini, V. Graphene Plasmonic Fractal Metamaterials for Broadband Photodetectors. Sci. Rep. 2020, 10, 1-10. [CrossRef]

26. Xia, F.; Mueller, T.; Lin, Y.M.; Valdes-Garcia, A.; Avouris, P. Ultrafast graphene photodetector. Nat. Nanotechnol. 2009, 4, 839-843. [CrossRef]

27. Guo, J.; Li, J.; Liu, C.; Yin, Y.; Wang, W.; Ni, Z.; Fu, Z.; Yu, H.; Xu, Y.; Shi, Y.; et al. High-performance silicon-graphene hybrid plasmonic waveguide photodetectors beyond $1.55 \mu \mathrm{m}$. Light Sci. Appl. 2020, 9. [CrossRef]

28. Mišeikis, V.; Marconi, S.; Giambra, M.A.; Montanaro, A.; Martini, L.; Fabbri, F.; Pezzini, S.; Piccinini, G.; Forti, S.; Terrés, B.; et al. Ultrafast, Zero-Bias, Graphene Photodetectors with Polymeric Gate Dielectric on Passive Photonic Waveguides. ACS Nano 2020, 14, 11190-11204. [CrossRef]

29. Zhuo, L.; Fan, P.; Zhang, S.; Liu, X.; Guo, X.; Zhang, Y.; Zhan, Y.; Li, D.; Che, Z.; Zhu, W.; et al. A broadband all-fiber integrated graphene photodetector with CNT-enhanced responsivity. Nanoscale 2020, 12, 14188-14193. [CrossRef]

30. Gosciniak, J.; Rasras, M.; Khurgin, J.B. Ultrafast Plasmonic Graphene Photodetector Based on the Channel Photothermoelectric Effect. ACS Photonics 2020, 7, 488-498. [CrossRef]

31. Konstantatos, G.; Badioli, M.; Gaudreau, L.; Osmond, J.; Bernechea, M.; De Arquer, F.P.G.; Gatti, F.; Koppens, F.H.L. Hybrid grapheneĝquantum dot phototransistors with ultrahigh gain. Nat. Nanotechnol. 2012, 7, 363-368. [CrossRef] [PubMed] 
32. Pan, R.; Han, J.; Zhang, X.; Han, Q.; Zhou, H.; Liu, X.; Gou, J.; Jiang, Y.; Wang, J. Excellent performance in vertical graphene-C60graphene heterojunction phototransistors with a tunable bi-directionality. Carbon N. Y. 2020, 162, 375-381. [CrossRef]

33. Han, J.; He, M.; Yang, M.; Han, Q.; Wang, F.; Zhong, F.; Xu, M.; Li, Q.; Zhu, H.; Shan, C.; et al. Light-modulated vertical heterojunction phototransistors with distinct logical photocurrents. Light Sci. Appl. 2020, 9. [CrossRef] [PubMed]

34. Sun, Z.; Hasan, T.; Torrisi, F.; Popa, D.; Privitera, G.; Wang, F.; Bonaccorso, F.; Basko, D.M.; Ferrari, A.C. Graphene mode-locked ultrafast laser. ACS Nano 2010, 4, 803-810. [CrossRef]

35. Green, N.S.; Norton, M.L. Interactions of DNA with graphene and sensing applications of graphene field-effect transistor devices: A review. Anal. Chim. Acta 2015, 853, 127-142. [CrossRef]

36. Schedin, F.; Geim, A.K.; Morozov, S.V.; Hill, E.W.; Blake, P.; Katsnelson, M.I.; Novoselov, K.S. Detection of individual gas molecules adsorbed on graphene. Nat. Mater. 2007, 6, 652-655. [CrossRef]

37. Panth, M.; Cook, B.; Zhang, Y.; Ewing, D.; Tramble, A.; Wilson, A.; Wu, J. High-Performance Strain Sensors Based on Vertically Aligned Piezoelectric Zinc Oxide Nanowire Array/Graphene Nanohybrids. ACS Appl. Nano Mater. 2020, 3, 6711-6718. [CrossRef]

38. Chen, Z.; Wang, Z.; Li, X.; Lin, Y.; Luo, N.; Long, M.; Zhao, N.; Xu, J. Bin Flexible Piezoelectric-Induced Pressure Sensors for Static Measurements Based on Nanowires/Graphene Heterostructures. ACS Nano 2017, 11, 4507-4513. [CrossRef]

39. Lian, Y.; He, F.; Wang, H.; Tong, F. A new aptamer/graphene interdigitated gold electrode piezoelectric sensor for rapid and specific detection of Staphylococcus aureus. Biosens. Bioelectron. 2015, 65, 314-319. [CrossRef]

40. Zhu, S.E.; Krishna Ghatkesar, M.; Zhang, C.; Janssen, G.C.A.M. Graphene based piezoresistive pressure sensor. Appl. Phys. Lett. 2013, 102, 111-114. [CrossRef]

41. Xing, F.; Liu, Z.B.; Deng, Z.C.; Kong, X.T.; Yan, X.Q.; Chen, X.D.; Ye, Q.; Zhang, C.P.; Chen, Y.S.; Tian, J.G. Sensitive real-time monitoring of refractive indexes using a novel graphene-based optical sensor. Sci. Rep. 2012, 2, 1-7. [CrossRef] [PubMed]

42. Deng, X.; Tang, H.; Jiang, J. Recent progress in graphene-material-based optical sensors. Anal. Bioanal. Chem. 2014, $406,6903-6916$. [CrossRef] [PubMed]

43. Xing, F.; Meng, G.X.; Zhang, Q.; Pan, L.T.; Wang, P.; Liu, Z.B.; Jiang, W.S.; Chen, Y.; Tian, J.G. Ultrasensitive flow sensing of a single cell using graphene-based optical sensors. Nano Lett. 2014, 14, 3563-3569. [CrossRef] [PubMed]

44. Liang, X.Y.; Ding, N.; Ng, S.P.; Wu, C.M.L. Adsorption of gas molecules on Ga-doped graphene and effect of applied electric field: A DFT study. Appl. Surf. Sci. 2017, 411, 11-17. [CrossRef]

45. Mehdi Pour, M.; Lashkov, A.; Radocea, A.; Liu, X.; Sun, T.; Lipatov, A.; Korlacki, R.A.; Shekhirev, M.; Aluru, N.R.; Lyding, J.W.; et al. Laterally extended atomically precise graphene nanoribbons with improved electrical conductivity for efficient gas sensing. Nat. Commun. 2017, 8, 1-9. [CrossRef]

46. Yang, S.; Lei, G.; Xu, H.; Xu, B.; Li, H.; Lan, Z.; Wang, Z.; Gu, H. A DFT study of CO adsorption on the pristine, defective, In-doped and Sb-doped graphene and the effect of applied electric field. Appl. Surf. Sci. 2019, 480, 205-211. [CrossRef]

47. He, Q.; Wu, S.; Yin, Z.; Zhang, H. Graphene-based electronic sensors. Chem. Sci. 2012, 3, 1764-1772. [CrossRef]

48. Wang, Z.; Yi, K.; Lin, Q.; Yang, L.; Chen, X.; Chen, H.; Liu, Y.; Wei, D. Free radical sensors based on inner-cutting graphene field-effect transistors. Nat. Commun. 2019, 10. [CrossRef]

49. Ahn, S.R.; An, J.H.; Jang, I.H.; Na, W.; Yang, H.; Cho, K.H.; Lee, S.H.; Song, H.S.; Jang, J.; Park, T.H. High-performance bioelectronic tongue using ligand binding domain T1R1 VFT for umami taste detection. Biosens. Bioelectron. 2018, 117, 628-636. [CrossRef]

50. Thakur, B.; Zhou, G.; Chang, J.; Pu, H.; Jin, B.; Sui, X.; Yuan, X.; Yang, C.H.; Magruder, M.; Chen, J. Rapid detection of single E. coli bacteria using a graphene-based field-effect transistor device. Biosens. Bioelectron. 2018, 110, 16-22. [CrossRef]

51. Chen, B.; Liu, H.; Li, X.; Lu, C.; Ding, Y.; Lu, B. Fabrication of a graphene field effect transistor array on microchannels for ethanol sensing. Appl. Surf. Sci. 2012, 258, 1971-1975. [CrossRef]

52. Kwak, Y.H.; Choi, D.S.; Kim, Y.N.; Kim, H.; Yoon, D.H.; Ahn, S.S.; Yang, J.W.; Yang, W.S.; Seo, S. Flexible glucose sensor using CVD-grown graphene-based field effect transistor. Biosens. Bioelectron. 2012, 37, 82-87. [CrossRef]

53. Zhang, Z.; Zou, X.; Xu, L.; Liao, L.; Liu, W.; Ho, J.; Xiao, X.; Jiang, C.; Li, J. Hydrogen gas sensor based on metal oxide nanoparticles decorated graphene transistor. Nanoscale 2015, 7, 10078-10084. [CrossRef] [PubMed]

54. Kwong Hong Tsang, D.; Lieberthal, T.J.; Watts, C.; Dunlop, I.E.; Ramadan, S.; del Rio Hernandez, A.E.; Klein, N. Chemically Functionalised Graphene FET Biosensor for the Label-free Sensing of Exosomes. Sci. Rep. 2019, 9, 2-11. [CrossRef]

55. Kim, C.-H.; Yoo, S.-W.; Nam, D.-W.; Seo, S.; Lee, J.-H. Effect of Temperature and Humidity on $\mathrm{NO}_{2}$ and $\mathrm{NH}_{3} \mathrm{Gas}_{\mathrm{Sensitivity}}$ of Bottom-Gate Graphene FETs Prepared by ICP-CVD. IEEE Electron Device Lett. 2012, 33, 1084-1086. [CrossRef]

56. Kai Zhang, L.Z. Volatile Organic Compounds as Novel Markers for the Detection of Bacterial Infections. Clin. Microbiol. Open Access 2014, 3. [CrossRef]

57. Elmassry, M.M.; Piechulla, B. Volatilomes of Bacterial Infections in Humans. Front. Neurosci. 2020, 14, 1-11. [CrossRef] [PubMed]

58. Roslund, K.; Lehto, M.; Pussinen, P.; Groop, P.-H.; Halonen, L.; Metsälä, M. On-line profiling of volatile compounds produced in vitro by pathogenic oral bacteria. J. Breath Res. 2019, 14, 016010. [CrossRef]

59. Kim, J.H.; Mirzaei, A.; Kim, H.W.; Kim, S.S. Improving the hydrogen sensing properties of SnO2 nanowire-based conductometric sensors by Pd-decoration. Sens. Actuators B Chem. 2019, 285, 358-367. [CrossRef]

60. Sharma, A.; Arya, S. Economical and Efficient Electrochemical Sensing of Folic Acid using a Platinum Electrode Modified with Hydrothermally Synthesized Pd and Ag Co-Doped $\mathrm{SnO}_{2}$ Nanoparticles. J. Electrochem. Soc. 2019, 166, B1107-B1115. [CrossRef] 
61. Zhang, D.; Li, Q.; Li, P.; Pang, M.; Luo, Y. Fabrication of Pd-Decorated $\mathrm{MoSe}_{2}$ nanoflowers and density functional theory simulation toward ammonia sensing. IEEE Electron. Device Lett. 2019, 40, 616-619. [CrossRef]

62. Liu, B.; Xu, Y.; Li, K.; Wang, H.; Gao, L.; Luo, Y.; Duan, G. Pd-Catalyzed Reaction-Producing Intermediate $\mathrm{S}$ on a Pd/In ${ }_{2} \mathrm{O}_{3}$ Surface: A Key to Achieve the Enhanced CS $_{2}$-Sensing Performances. ACS Appl. Mater. Interfaces 2019, 11, 16838-16846. [CrossRef] [PubMed]

63. Zhang, Y.H.; Li, Y.L.; Gong, F.L.; Xie, K.F.; Zhang, H.L.; Fang, S.M. Double-platelet Pd@ZnO microcrystals for NO 2 chemical sensors: Their facile synthesis and DFT investigation. Phys. Chem. Chem. Phys. 2019, 21, 22039-22047. [CrossRef] [PubMed]

64. Zhang, Y.H.; Wang, C.N.; Gong, F.L.; Wang, P.; Guharoy, U.; Yang, C.; Zhang, H.L.; Fang, S.M.; Liu, J. Ultrathin agaric-like ZnO with Pd dopant for aniline sensor and DFT investigation. J. Hazard. Mater. 2020, 388, 122069. [CrossRef] [PubMed]

65. Montemore, M.M.; Medlin, J.W. A unified picture of adsorption on transition metals through different atoms. J. Am. Chem. Soc. 2014, 136, 9272-9275. [CrossRef] [PubMed]

66. Khodadadi, Z. Evaluation of $\mathrm{H}_{2} \mathrm{~S}$ sensing characteristics of metals-doped graphene and metals-decorated graphene: Insights from DFT study. Phys. E Low-Dimens. Syst. Nanostruct. 2018, 99, 261-268. [CrossRef]

67. Bo, Z.; Guo, X.; Wei, X.; Yang, H.; Yan, J.; Cen, K. Density functional theory calculations of $\mathrm{NO}_{2}$ and $\mathrm{H}_{2} \mathrm{~S}$ adsorption on the group 10 transition metal (Ni, Pd and Pt) decorated graphene. Phys. E Low-Dimens. Syst. Nanostruct. 2019, 109, 156-163. [CrossRef]

68. Wong, J.; Yadav, S.; Tam, J.; Veer Singh, C. A van der Waals density functional theory comparison of metal decorated graphene systems for hydrogen adsorption. J. Appl. Phys. 2014, 115. [CrossRef]

69. Zhang, X.; Yu, L.; Wu, X.; Hu, W. Experimental Sensing and Density Functional Theory Study of $\mathrm{H}_{2} \mathrm{~S}$ and $\mathrm{SOF}_{2} \mathrm{Adsorption}$ on Au-Modified Graphene. Adv. Sci. 2015, 2, 1-10. [CrossRef]

70. Poh, H.L.; Šimek, P.; Sofer, Z.; Pumera, M. Halogenation of graphene with chlorine, bromine, or iodine by exfoliation in a halogen atmosphere. Chem. A Eur. J. 2013, 19, 2655-2662. [CrossRef]

71. Huang, C.; Li, C.; Shi, G. Graphene based catalysts. Energy Environ. Sci. 2012, 5, 8848-8868. [CrossRef]

72. Cheng, S.H.; Zou, K.; Okino, F.; Gutierrez, H.R.; Gupta, A.; Shen, N.; Eklund, P.C.; Sofo, J.O.; Zhu, J. Reversible fluorination of graphene: Evidence of a two-dimensional wide bandgap semiconductor. Phys. Rev. B Condens. Matter Mater. Phys. 2010, 81, 1-5. [CrossRef]

73. López-Corral, I.; Germán, E.; Juan, A.; Volpe, M.A.; Brizuela, G.P. DFT Study of Hydrogen Adsorption on Palladium Decorated Graphene. J. Phys. Chem. C 2011, 115, 4315-4323. [CrossRef]

74. Walia, G.K.; Randhawa, D.K.K. Adsorption and dissociation of sulfur-based toxic gas molecules on silicene nanoribbons: A quest for high-performance gas sensors and catalysts. J. Mol. Model. 2018, 24. [CrossRef] [PubMed]

75. Valizadeh, P. Electronic Materials and Charge Transport. In Field Effect Transistors, A Comprehensive Overview; John Wiley \& Sons, Inc.: Hoboken, NJ, USA, 2016; pp. 1-118.

76. Patterson, J.D.; Bailey, B.C. Semiconductors. In Solid State Physics; Springer: Berlin, Germany, 2018; pp. $293-351$.

77. Green, M.A. Intrinsic concentration, effective densities of states, and effective mass in silicon. J. Appl. Phys. 1990, 67, 2944-2954. [CrossRef]

78. Gunst, T.; Markussen, T.; Stokbro, K.; Brandbyge, M. First-principles method for electron-phonon coupling and electron mobility: Applications to two-dimensional materials. Phys. Rev. B 2016, 93, 035414. [CrossRef]

79. Kaasbjerg, K.; Thygesen, K.S.; Jacobsen, K.W. Unraveling the acoustic electron-phonon interaction in graphene. Phys. Rev. B Condens. Matter Mater. Phys. 2012, 85, 165440. [CrossRef]

80. Haddad, P.A.; Flandre, D.; Raskin, J.P. Intrinsic rectification in common-gated graphene field-effect transistors. Nano Energy 2018, 43, 37-46. [CrossRef]

81. Hulko, M.; Hospach, I.; Krasteva, N.; Nelles, G. Cytochrome C biosensor-A model for gas sensing. Sensors 2011, 11, 5968-5980. [CrossRef]

82. Kubo, I.; Karube, I.; Takeuchi, B.; Furusawa, M.; Arikawa, Y.; Kanagawa, T. A biosensor based on Thiobacillus thioparus for measuring thiosulfate and methanethiol. Can. J. Microbiol. 1995, 41, 366-371. [CrossRef]

83. Hidalgo, F.; Rubio-Ponce, A.; Noguez, C. Tuning Adsorption of Methylamine and Methanethiol on Twisted-Bilayer Graphene. J. Phys. Chem. C 2019, 123, 15273-15283. [CrossRef] 